reflects in its presentation the excellent manner in which the lecture material must have been prepared and delivered. The imaging radar system is an interesting remote sensing technique which should find application in many branches of science and engineering, particularly those eoncerned with earth resource surveying. No electronic circuits appear in the book, only block and optical diagrams. The student of physical optics will find much which he recognizes, and, indeed, the author pays ample tribute to the contributions of Professor E. N. Leith to the understanding and success of SAR. This is a book to be recommended to the serious student of system design engineering and particularly to those who are engaged in current research in the field of high-resolution radar.

S. Weintroub

\section{COMPLEX VARIABLES}

\section{Functions of a Complex Variable}

By D. O. Tall. Vols. 1 and 2. (Library of Mathematics.) Vol. 1: Pp. 72. Vol. 2: Pp. 80. (Routledge and Kegan Paul: London; Dover: New York, July 1970.) 18s boards; $9 s$ paper (each).

THIs subject is one of the pleasantest in the undergraduate course. Theorems are easy to comprehend, though not always to prove, and applications are varied and fascinating; as Littlewood has said, everybody is struck on first meeting with the calculation of definite integrals by contour integration, and to this one might perhaps add conformal mapping.

The author assumes a knowledge of complex numbers, such as may be obtained from Ledermann's book in the same series, and is therefore able to discuss straightaway the topics of differentiation, integration and Taylor series. When topological properties are involved, these are clearly stated but proofs are generally omitted; most students at this stage will be prepared to accept, for instance, Jordan's curve theorem as a reasonable assumption. Cauchy's theorem is proved by means of the Stokes formula, but a proof under less restrictive conditions is given for a triangle; the step from here to the general result is again a matter for topology.

The second volume deals with applications. There is a somewhat brief introduction to conformal mapping and harmonic functions. Then we have a good account of the calculus of residues and applications, particularly to definite integrals; here the author deals carefully with principal values. The final chapter concerns analytic continuation and Riemann surfaces. In twelve small pages, only a very cursory account can be provided, and its chief use should be to whet the reader's appetite for further study.

Exercises are kept at an elementary level, and are not so numerous as to daunt the student: solutions are supplied.

T. A. A. Broadbent

\section{DATA FOR TOXICOLOGISTS}

\section{Handbook of Analytical Toxicology}

Edited by Irving Sunshine. Pp. xiv +1081 . (Chemical Rubber: Ohio; Blackwell (Scientific): Oxford, 1969.) $280 \mathrm{~s}$.

THis book is claimed to be a collection of data essential to scientists engaged in the analysis of drugs, poisons, and industrial chemicals. It is compiled on similar lines to the well known Handbook of Chemistry and Physics, from the same publisher. Types of compounds covered include drugs (the largest group, occupying about 550 pages), pesticides, described as economic poisons (113 pages), industrial chemicals (confined to those for which American threshold limit values are available) (98 pages), and smaller sections on air pollution and water analysis.

The drugs selocted are those considered to be of greatest interest to toxicologists, and inorganic compounds are excluded. Much useful data are given on toxicity, metabolism and excretion, isolation procedures and identifica. tion. Sections are included on micro melting point determinations and microcrystal tests. Ultraviolet absorption data are given for many drugs and spectra are reproduced for 290 compounds. Infrared spectra, with tables to enable many pharmaceuticals and pesticides to be identified through the well known Sadtler collection, are also provided. Large sections are devoted to chromatographic data (paper, thin layer and gas), giving $R_{F}$ values or retention times in many systems, and details of detection reagents. Physical methods of analysis aro discussed, including infrared, fluorescence and atomic absorption spectrometry, microdiffusion analysis, and chromatography.

A criticism might be that information on a particular subject, such as ultraviolet spectroseopy or chromatography, is divided among several sections in different parts of the book. 'This is, however, probably inevitable when so much material on different groups of compounds is collected in one volume, and in practice it is not difficult to find the required data.

Like other well known CRC publications this book is very thorough and detailed in its information. The tables are well supplied with references which greatly increases thoir usefulness. Many references as recent as 1968 are included. There is a comprehensive index.

The information provided is so vast that the book can hardly fail to be useful to anybody working in the field of drugs or toxicology. The book is strongly bound and well presented, which is to be expected in view of its high cost. Further cditions are promised to bring the contents up to date in a field which is inevitably changing rapidly.

A. R. MatTocks

\section{TOXIN TREATISE}

\section{Microbial Toxins}

A Comprehensive Treatise. Edited by Samuel J. Ajl, Soloman Kadis and Thomas C. Montie. Vol. 1: Bacterial Protein Toxins. Pp. xxii +517 . (Academic: New York and London, April 1970.) 215s.

IF workers on bacterial toxins have been able to complain, with justice, that there has been no book on their subject since a slim volume in 1951 and very patchy coverage by review articles, they can do so no longer. This is the first volume of a set of six which will deal with the bacterial protein toxins in three volumes, the endotoxins in two, and the algal and fungal toxins in the final one. The names of the authors of some projected chapters are a sufficient guarantee that their subjects will be dealt with adequately.

This volume provides a general survey of the protein toxins and has an admirable introductory chapter by van Heyningen, the author of the 1951 book. Then follow a chapter on nomenclature by Bonventre and two excellent chapters by Raynaud and Alouf on the kinetics of toxin formation and release, and on methods of purification and the properties of the purified toxins, followed by an equally good one on eytolytic toxins by Bernheimer. Both Bonventre and Raynaud and Alouf discuss the classification of toxins and come up with quite different answers to what is a thorny, but not fundamentally important, problem. Indeed, the freedom which the cditors have allowed their authors has produced even more duplication than is usual in multi-author works and has also led to some lacunae. Thus, the discussion by Bullen of enterotoxaemia in sheep and gas gangrene in man, produced by different Clostridium welchii strains, makes an important point about the difficulty of determining the role of toxins in the pathology of some discases, but is the only chapter on pathology in the book, although there is an excellent summary of recent work on toxin 